\title{
A RELAÇÃO TEORIA E PRÁTICA NO PROCESSO DE FORMAÇÃO DOCENTE
}

Willyan Ramon de Souza Pacheco, Universidade Federal de Campina Grande (UFCG),

$$
\text { pachecowillyan8@gmail.com }
$$

João Paulo da Silva Barbosa, Universidade Federal de Campina Grande (UFCG), joaopaulo08barbosa@hotmail.com

Dorgival Gonçalves Fernandes, Universidade Federal de Campina Grande (UFCG), dorgefernandes@yahoo.com.br

\section{RESUMO}

As relações teóricas e práticas que circundam o processo de formação docente são pautas de vários estudos na contemporaneidade. A prática que é desenvolvida de modo a relacionar os saberes epistemológicos apreendidos e as experiências vivenciadas no processo de formação docente, por vezes se distancia do real objetivo da ação pedagógica que é a relação teoria e prática. Nessa perspectiva, discutiremos neste artigo acerca dessa relação, dando ênfase ao modo como a dicotomia ou a unificação de ambas podem influenciar na constituição da formação do educador. Essa relação que abordamos como indispensável e constituinte para o processo de construção do profissional docente dar-se pelo entendimento de que não existe teoria sem prática e vice-versa. Este artigo se materializa a partir de pesquisa bibliográfica de natureza exploratória, na qual empregamos leituras de artigos, trabalhos de conclusão de curso e discussões realizadas em sala de aula sobre este tema. Evidencia-se nesse trabalho a relevância das dimensões teórica e prática no processo de formação e atuação docente, configurando-se em um movimento integrativo oportunizando a construção $e \quad a$ ressignificação da práxis docente.

PALAVRAS-CHAVE: Formação docente; Teoria e Prática; Práxis.

THE RELATIONSHIP THEORY AND PRACTICE IN THE PROCESS OF TEACHER TRAINING

\begin{abstract}
We will discuss in this article about the theory-practice relationship, emphasizing how a dichotomy or a unification of all influences in the formation of the educator's training. We use as theoretical contribution bibliographical research of an exploratory nature, such as: articles, course completion work and discussions held in the classroom. It concludes in the work the relevance of the dimension theory and practice in the process of construction and resignification of teaching praxis.
\end{abstract}


KEYWORDS: Teacher training; Theory and practice; Praxis.

\section{LA RELACIÓN TEORÍA Y PRÁCTICA EN EL PROCESO DE FORMACIÓN DOCENTE \\ RESUMEN}

Discutiremos este artículo sobre la relación teoria-práctica, dando la forma de una dicotomía o una unificación de las dos formas de influenciar en la constitución de la formación del educador. Utilizamos como aporte teórico investigaciones bibliográficas de naturaleza exploratoria, como: artículos, trabajos de la conclusión del curso y discusiones realizadas en la sala de aula. Conclui-se en este trabajo una relevancia de la dimensión teórica y la práctica no proceso de construcción y la reestructuración de la práxis docente.

PALABRAS CLAVE: Formación docente; Teoría y Práctica; Práxis.

\section{INTRODUÇÃO}

O docente é um sujeito constituído por relações, relações entre professor e aluno, escola e sociedade, teorias e práticas pedagógicas, entre outras. Estas efetivam de forma significativa o processo de formação do professor, fazendo com que este tenha condições de desenvolver seus conhecimentos e saberes epistemológicos, sendo assim norteado para desempenhar com propriedade e competência sua função educacional.

$\mathrm{Na}$ contemporaneidade, várias discussões têm como pauta essas relações, a exemplo do que fazem Guedes e Schelbauer (2009) e de como a ausência delas podem afetar o processo de aprendizagem do aluno e a formação do professor, partindo do pressuposto que o docente está em exercício contínuo de aprendizagem e construção de conhecimentos.

Nessa perspectiva, discutiremos neste estudo questões que circundam a relação teoria e prática, dando ênfase ao modo de como a dicotomia ou a unificação de ambas podem influenciar na constituição da formação do educador, afetando de forma positiva ou negativa a atuação docente.

Nessa acepção, a indagação que norteia este trabalho é a seguinte: Quais as contribuições e limitações que a unificação ou separação da relação teoria-prática oportunizam na condução do processo de formação e profissionalização docente, afetando-o de forma direta a sua práxis?

Sob essa perspectiva, o que buscamos analisar são as teorias e técnicas apreendidas ao longo da formação acadêmica em cursos de formação de professores, relacionando o processo 
de ensino/aprendizagem e evidenciando como essas configuram-se em prática nas salas de aula de instituições de ensino após a formação docente. Neste sentido, buscamos analisar de modo sistemático as contribuições da relação teoria-prática nesse processo de formação, observando como ocorre a unificação e como se pode construir uma relação integrativa entre ambas, satisfazendo as necessidades do processo de formação e de ensino e aprendizagem e valorizando os conhecimentos apreendidos pelo educador.

A base metodológica deste trabalho se constitui como pesquisa bibliográfica de natureza exploratória, a partir de leituras de artigos, trabalhos de conclusão de curso e discussões realizadas em sala de aula sobre o referido tema.

\section{BINÔMIO TEORIA E PRÁTICA}

O processo de formação dos professores é um dos assuntos mais debatidos na atualidade. Esse processo que acontece de modo contínuo, trata-se de como o sujeito será constituído como futuro educador, retratando, portanto, como construirá seu saber docente e seus conhecimentos, práticas pedagógicas e metodologias, teorias e conceitos. Dessa forma, o docente será norteado para desenvolver suas competências como futuro profissional da educação, mediando uma relação entre o espaço escolar e a realidade de cada educando, desenvolvendo assim o saber-fazer que privilegiará tanto a sua formação quanto o processo de ensino-aprendizagem do discente.

O binômio que circunda esse referido processo é a relação teoria e prática que possui relevância significativa na formação dos professores e alunos. Essa relação é caracterizada por uma trajetória histórica com perspectiva dicotômica que acaba afetando de forma negativa o desenvolvimento dos saberes docentes. Assim, Santos (2014, p. 8), reflete:

\footnotetext{
Nesse debate sobre qualificação docente a temática da relação teoria e prática tem ganhado relevância, haja vista o potencial formativo de que este binômio se reveste, bem como pela perspectiva dicotômica com a qual o mesmo historicamente tem sido conduzido em configurações curriculares e práticas de formação.
}

A teoria é a forma como o conhecimento se apresenta articulando-se sistematicamente em graus e especificidades, disposto a explicar ou ilustrar ações práticas; enquanto a prática é a constituição da teoria, formulada em ações concretas, podendo ser modificada e modificar as teorias. Considerando esse contexto, fica evidente que ambas se entrelaçam e que a 
desvinculação destas fragiliza o processo de aprendizagem do sujeito. Sobre isso, Dutra (2009, p. 2) aponta:

Teoria é "um conjunto de conhecimentos não idênticos nem totalmente distintos da prática, mas provenientes desta através de uma análise crítica que tem por finalidade, no seu retorno à prática, esclarecê-la e aperfeiçoá-la" [...] e prática é "um saber objetivo e traduzido em ação".

Dessa maneira, tratando das teorias pedagógicas que sustentam a ação docente podemos evidenciar o percurso formativo destas para a transformação da prática. Sendo a teoria a força intencional que possibilita o saber docente consolidar-se no fazer-se docente, materializando os conceitos originados no âmbito de sua formação, direcionando-o a reflexões recorrentes que tem por objetivo ressignificar sua prática docente e assim construir sua práxis.

Compreende-se que o discente em formação necessita articular, sistematizar e aperfeiçoar os saberes através da unicidade teoria-pratica, pois dessa maneira estará produzindo conhecimento para si, para que, como futuro educador, possa tornar a educação significativa para os educandos.

O professor é visto como o profissional da educação que possui aptidão e competência para "organizar, sistematizar e hierarquizar idéais" (BRZEZINSKI, 1998, p. 169), sendo capaz de planejar e desenvolver de forma dinâmica e significativa um modo coerente de aplicar essas ideias em sua prática docente, efetivando o saber-fazer e aperfeiçoando sua ação pedagógica.

Durante a formação dos discentes, enquanto futuros educadores, é imprescindível que no decorrer do curso haja práticas pedagógicas em espaços escolares, pois estas contribuem na construção do saber empírico que advém dos estágios presentes nos cursos de formação de professores ou até mesmo em projetos desenvolvidos pelas instituições de ensino.

Atualmente, o cenário de profissionalização docente se centraliza em um emaranhado de teorias que têm como objetivo o aperfeiçoamento profissional do professor, isso quando sua formação já tem se concluído, partindo assim para uma formação continuada. Assim, percebemos que tanto a profissionalização, quanto a formação são determinantes para qualificação profissional do sujeito docente, logo, são nelas que o professor constrói seus primeiros saberes e conhecimentos acerca da profissão. 
A formação inicial de professores é entendida como o alicerce de toda sua construção como futuro educador. Daí vê-se a relevância que a relação teoria-prática possui nessa primeira fase de sua formação, pois dessa maneira, o discente perceberá desde cedo o possível cenário e a realidade que o cercará durante sua carreira profissional. Com isso, lhe será oportunizado desenvolver práticas emancipatórias vinculadas às teorias com destreza e autonomia, tendo um pensamento consciente de que sua formação não se limita ao espaço acadêmico, mas sim é uma construção contínua, construindo saberes, conhecimentos e vivenciando experiências dentro e fora das instituições.

Observa-se nesse contexto que a teoria e a prática pedagógica estão estreitamente ligadas por um fio que conduz ao ensino, porém vale salientar que a dimensão teórica e prática não está presente apenas nos espaços educacionais, mas em todo o exercício que direciona o sujeito à ação. Souza (2001) nos mostra que qualquer produção intelectual que tenha por objetivo levar a uma ação concreta de produção é uma prática, seja ela pedagógica ou não. Porém, manteremos nosso foco na teoria-prática pedagógica que é o que nos interessa analisar nesse momento.

Uma das problemáticas que circundam o processo de formação docente é o uso dicotômico da teoria e da prática, pois essa dissociação fragiliza a atuação docente, fragmentando a capacidade de o sujeito agir de forma consciente, separando-o da realidade que irá enfrentar. Essa dicotomia traz riscos à própria educação, pois, talvez, o professor não saberá se nortear em busca de uma aprendizagem significativa, ficando impossibilitado de construir e ressignificar sua ação pedagógica.

Nessa perspectiva, o docente terá menos possibilidades para pensar de forma sistemática sobre suas práticas pedagógicas, dificultando o desenvolvimento de sua criticidade para questionar os fatos que o rodeiam e entender o porquê de suas ações, afetando assim sua autonomia, fragilizando sua prática educacional e desqualificando sua ação docente.

Sabendo que existe essa dicotomia no processo de formação docente, partiremos para uma explicação particular da teoria e da prática. Quando falamos em prática, não nos referimos em reprodução, mas sim em produção, produzir conhecimentos que antes já estudados, para uma realidade a qual está se vivendo, de modo contextualizado, viabilizando 
interações constrtutivas para uma melhor compreensão e apreensão do conhecimento partindo do educador/educando. Dessa maneira, Souza (2001, p.6) nos afirma:

Reconhecer que a finalidade maior da tarefa educativa não é, apenas, a mera transmissão metódica e ordenada do saber sistematizado pela humanidade, mas que é, fundamentalmente, estabelecer novas formas de produzir e distribuir o conhecimento - orientado para novas formas de conceber o mundo, o trabalho, as relações sociais e de vida - suscita a necessidade de entender a prática pedagógica como um processo que tem como ponto de partida e de chegada a prática social.

Sabemos que para haver essa estruturação prática é necessário que antes exista a teoria, esta vem para dar base a esse processo com a construção de métodos que se referem ao ensino. Mas como essa teoria é constituída e influenciada para levar para as escolas um método padrão de prática? Podemos observar o que SOUZA (2001, p.5) nos traz:

Os professores foram preparados - pelas instituições de ensino que frequentaram, pelas muitas experiências que vivenciaram enquanto alunos e enquanto educadores - para a subserviência, para a reprodução da ordem social vigente, para a imutabilidade das coisas.

Analisamos que, quando as teorias adquiridas em meio à formação vão de encontro com a instituição a qual o docente é direcionado, surge a ordem, as regras e todo o regulamento que por vezes impossibilita que a teoria seja estabelecida tal qual foi pensada e estudada, repreendendo a socialização do conhecimento, isso porque cada instituição tem seu conjunto de normas que acaba por censurar o novo.

Ainda nessa perspectiva particular de teoria e prática, é necessário dizer que havendo uma dicotomia, não é possível estabelecer uma ação significativa, que tenha sentido e objetivo, logo uma teoria sem prática minimiza as habilidades do professor voltadas à compreensão, construção, elucidação e transformação seja numa instituição, seja na própria educação.

Sendo assim, se a teoria e a prática forem realizadas de formas separadas ou isoladas não produzirão resultados significativos, partindo do pressuposto de que uma não é superior à outra, já que a teoria se origina da atividade prática, e essa última fundamenta-se em uma teoria, para que assim haja um aprimoramento de ambas de forma coerente. Nesse sentido, pode-se dizer que há uma interdependência entre as mesmas, como se fosse um ciclo em que uma necessita da outra para se complementar. Nessa perspectiva, Souza (2001, p.7) nos mostra: 
Ao isolar a teoria da prática ou a prática da teoria, os processos de formação abalam a capacidade do educador de pensar sobre a ação pedagógica, de compreender a estrutura da escola, de aclarar os propósitos da educação, de elucidar as formas de existência e de organização social, em toda sua complexidade e historicidade e [...] de recriá-las, de transformá-las, de superá-las.

É válido enfatizar que a teoria e a prática são componentes indissociáveis na constituição do processo de formação do professor e:

São, portanto, componentes indissolúveis da —práxis, definida como atividade teórico-prática que inclui um lado ideal, teórico, e um lado material, propriamente prático, que só podem ser separados por um processo de abstração (VÁSQUEZ, 1977 apud SANTOS, 2014, p. 85).

Dessa forma, quando mantemos a relação entre ambas, esse processo se torna amplamente harmônico e complementar. Teorias e práticas pedagógicas que são naturalmente diferentes, quando se trata da realidade encontrada na escola, se complementam e fazem o saber pedagógico ganhar sentido e significado, com objetivos para (re) criar novos métodos de ensino e metodologias lúdicas e atrativas, com isso, o trabalho pedagógico torna-se claro e compreensível.

Essa relação não só favorece o docente, como também beneficia a escola com mais conhecimentos e predisposição para colocar em prática saberes adquiridos na formação docente. Souza (2001, p. 7) nos traz essa complementaridade de teoria e prática e nos mostra isso claramente quando diz:

Teoria e prática constituem um todo único, produzido na dinâmica da evolução humana em um contexto e em um tempo. Não há prevalência de uma sobre a outra, há interdependência. Não há determinação de uma em relação à outra, há reciprocidade. Não há reticências de uma para outra, há dinamicidade.

No que se refere à práxis docente pode-se dizer que a mesma está inclusa em um movimento entre teoria e prática, fazendo uma mediação entre ambas e as aprimorando, dessa forma, tanto a teoria como a prática se contemplam em um conjunto de interdependência. A práxis seria assim o ápice da prática pedagógica quando esta retorna de forma reflexiva para a teoria, num processo de amadurecimento e aperfeiçoamento de suas ações docente, estaria a teoria amadurecida, reflexiva e humanizada, com uma prática significativa, interdisciplinar e lúdica.

A teoria não estaria apenas criando a possibilidade de uma ação, instituindo-se somente como resultado da prática, mas também mediando uma reflexão sobre a própria 
prática, para posteriormente voltar novamente para si e encontrar-se com a plenitude docente, a práxis (SOUZA, 2001). Essa postura reflexiva direciona e ressignifica a ação docente de modo a transformar, enriquecer e aprimorar seus estudos para construir saberes significativos no processo de ensino-aprendizagem dos discentes, oportunizando experiências autoformativas constituintes do processo de profissionalização docente.

\section{CONSIDERAÇÕES PROVISÓRIAS}

Diante dos fatos abordados, evidenciamos que a relação teoria e prática é um dos fatores determinantes para a constituição e aprimoramento da práxis docente, além disso, essa referida relação que consideramos mútua e inexoravelmente imprescindível no processo de formação docente,vem a ser o alicerce para o processo de amadurecimento e reflexão pedagógica.

Assim, concluímos que a dicotomização da relação teoria e prática fragiliza a formação do profissional docente como também sua ação educacional, minimizando os caminhos para desenvolver práticas significativas, dificultando o processo de ressignificação da prática por meio de uma ação critico-reflexiva, no qual o sujeito reflete acerca das ações desenvolvidas.

Nessa perspectiva, quando o professor compreende a interdependência que a teoria e a prática possuem uma sobre a outra e faz uso dessa concepção em sua ação docente, este tornase reflexivo direcionando sua prática a estágios significativos que possibilitam e contribuem para a construção de uma identidade emancipatória, conduzindo assim os sujeitos discentes à emancipação.

Portanto, a ação-reflexão-ação, que constitui a práxis, oportuniza ao docente ressignificar seus conceitos, teorias, práticas e saberes. Possibilitando assim, maior compreensão do contexto educacional ao qual está inserido, permitindo-se explorar novos horizontes que o conduzam a outras visões de ensino e educação, construindo-se e transformando-se cotidianamente.

\section{REFERÊNCIAS}


BRZEZINSKI, I. Notas sobre o currículo na formação de professores: teoria e prática. In: SERBINO, R. Q. et al. (Org.). Formação de professores. São Paulo: Fundação Editora da UNESP, 1998, p.161-74.

DUTRA, E. F. Relação entre Teoria e Prática em Configurações Curriculares de Cursos de Licenciatura. In: Anais do VII Encontro Nacional de Pesquisa em Educação em Ciências, Florianópolis/SC, 2009, p. 1-12.

GUEDES, S. T. R.; SCHELBAUER, A. R. Relação Teoria e Prática no Curso de Professores. In: Caderno de atividades e resumos do XVII COLE - Congresso de Leitura do Brasil. Campinas - SP: UNICAMP/FE, 2009. v. I. p. 621-622.

SANTOS, M. G. A relação teoria e prática na formação do pedagogo à luz do materialismo histórico-dialético. Feira de Santana: UEFS Editora, 2016, 298p.

SOUZA, N. A. A relação teoria-prática na formação do educador. In: Anais da Semana de Ciências Sociais e Humanas, Londrina, v. 22, p. 5-12, 2001.

TROJAN, R. M. Teoria e Prática na Formação Docente: estudo das políticas educacionais brasileiras e cubanas. In: I Encuentro Latinoamericano de Estudios Comparados en Educación, 2007, Buenos Aires - Argentina. I Encuentro Latinoamericano de Estudios Comparados en Educación: hacia una educación de calidad para todos - desafios para la perspectiva comparada. Buenos Aires: SAECE, 2007. v. 1. p. 1-15. 